\title{
Um olhar sobre a Geodiversidade do Parque Estadual da Pedra da Boca (PE/PB)
}

\author{
A look at the geodiversity of the State Park of Pedra da Boca (PEPB)
}

\author{
BARBOSA $^{1}$, E. N.; $\operatorname{MENESES}^{2}$, L. F.; CAVALCANTE ${ }^{3}$, M. B.
}

elisabetee.n.b@hotmail.com

\begin{abstract}
Resumo
O estado da Paraíba possui uma geodiversidade expressiva, com inúmeras feições geológicas e geomorfológicas, as quais podem ser utilizadas para fins geoturísticos. Apresenta em todo o seu território um potencial geoturístico ímpar, com vários locais propícios para o desenvolvimento dessa atividade associada a diferentes tipos de patrimônios, sejam eles geológicos, geomorfológicos, paleontológicos, arqueológicos, entre outros. Um destes lugares é o Parque Estadual da Pedra da Boca (PEPB), localizado no município de Araruna/PB, sobre o qual este trabalho se debruça buscando, como objetivo principal, produzir uma síntese sobre os valores da geodiversidade que nele se verificam. Para atingir os objetivos, efetuou-se uma revisão bibliográfica referente ao tema, além de trabalhos de campo. Os resultados obtidos demonstram a ocorrência de 6 valores e 15 subvalores da geodiversidade na área do PEPB. Concluise que o PEPB apresenta expressivos valores cultural, intrínseco, funcional e científico/educacional, que podem ser mais bem trabalhados para desenvolver novas vertentes do turismo que sejam mais adequadas às características ambientais daquela UC, a exemplo do geoturismo.
\end{abstract}

Palavras-chave: Turismo, Geodiversidade, Unidades de Conservação.

\begin{abstract}
The state of Paraiba has an expressive biodiversity with numerous geological and geomorphological features, which can be used to geotouristic purposes. It presents throughout its territory an unique geotouristic potential, with several potential places for the development of such activity associated with different types of patrimonies, whether geological, geomorphological, paleontological, archaeological, among others. One of these places is the State Park of Pedra da Boca (PEPB), located in the city of Araruna / PB, on which this work is focused to produce, as its main objective, a synthesis of the values of its geodiversity. To achieve the objectives, we performed a literature review concerning the issue, as well as field work. The results show the occurrence of 6 values, and 15 subvalues of geodiversity in PEPB area. It is concluded that the PEPB presents significant values as cultural, intrinsic, functional and scientific / educational, that can best be worked to develop new aspects of tourism that are more appropriate to the environmental characteristics of this CU (Conservation Unit), as an example the geotourism.
\end{abstract}

Keywords: Tourism; Geodiversity; Conservation Units.

\section{INTRODUÇÃO}

O turismo cada vez mais vem participando de forma significativa na composição de forças que regem a economia mundial. A globalização; o emprego de novas tecnologias, que contribuem para diminuir as distâncias entre destinos e aproximar os viajantes do local a ser visitado; as mudanças nas relações de trabalho; concessão de férias; adoção de viagens de incentivo; entre outros fatores, fizeram com que o turismo se tornasse, além de uma tendência, uma importante atividade econômica (SEBRAE, 2010). Sob esse ponto de vista, portanto, o turismo contribui positivamente na geração de emprego e renda, melhorando a qualidade de vida de milhares de pessoas. 
Uma das características do turismo é a constante busca por novos atrativos com belezas cênicas para seu desenvolvimento, explorando-os com o intuito da realização de atividades de lazer e recreação. Nos últimos anos, por exemplo, tem se desenvolvido a prática de uma modalidade denominada de geoturismo, que corresponde, segundo Mantesso-Neto (2010), a um turismo em que além da fruição visual, o turista recebe informações sobre a "base geológica" do que ele está vendo e sobre o valor e a necessidade da sua proteção.

Essa prática é cada vez mais comum entre as pessoas que procuram o chamado turismo de natureza para conhecer novos ambientes. Por dar destaque aos elementos da geodiversidade, o geoturismo surge como uma atividade importante na conservação, valorização e divulgação do geopatrimônio, que constitui parte integrante e essencial do patrimônio natural.

Apesar de ser um segmento novo, o geoturismo tem mostrado características específicas e essenciais à conservação do geopatrimônio e ao desenvolvimento econômico e social nas localidades onde é realizado (NASCIMENTO, RUCHKYS e MANTESSO-NETO, 2008a). Essas características seriam a junção dos atrativos turísticos com seus aspectos geológicos, que descrevem a história da Terra, e geomorfológicos que modelam o ambiente. Por meio destes conhecimentos, os turistas, visitantes e moradores locais passam a dar valor a estes locais e consequentemente a praticar a educação ambiental.

Para que os elementos da geodiversidade possam se converter em atrativos turísticos, estes devem ser estudados e suas características "traduzidas" para que o maior público possível tenha acesso e o devido entendimento de seu valor, seja compreender a evolução da história geológica da Terra, seja para verificar a intrínseca relação entre os meios abiótico, biótico e cultural, que compõem o ambiente.

O estado da Paraíba possui uma geodiversidade expressiva e com inúmeras feições geológicas e geomorfológicas, as quais podem perfeitamente ser utilizadas para fins geoturísticos. Apresenta em todo o seu território um potencial geoturístico ímpar, com vários locais propícios para o desenvolvimento dessa atividade associada a diferentes tipos de patrimônios, sejam eles geológicos, geomorfológicos, paleontológicos, arqueológicos, entre outros.

Um destes lugares é o Parque Estadual da Pedra da Boca (PEPB), localizado no município de Araruna/PB, sobre o qual este trabalho se debruça buscando, como objetivo principal, produzir uma síntese sobre os valores da geodiversidade que nele se verificam.

\section{METODOLOGIA}

A pesquisa consistiu basicamente em uma revisão bibliográfica sobre o Parque Estadual da Pedra da Boca (PEPB), visando construir uma visão de síntese dos principais elementos que compõem sua 
geodiversidade e os valores a eles associados, buscando-se ilustrá-los com exemplos claros e objetivos identificados na área do parque e de seu entorno imediato.

Para complementar a revisão bibliográfica, foram realizados trabalhos de campo nos dias 26 de julho de 2014, 19 de fevereiro de 2015 e 13 de maio de 2016, com o intuito de obter um levantamento fotográfico e coletar novos dados da área.

Para verificar os conteúdos que representam os valores da geodiversidade do parque, foi utilizada a proposta de Gray (2004) que os classifica em 07 categorias, conforme se apresenta a seguir:

-Valor Intrínseco (natureza abiótica independentemente da avaliação humana) expressa a relação que existe entre o homem e a natureza e é de difícil entendimento principalmente devido a dificuldade de quantificá-lo.

- Valor Cultural (folclore, arqueológico, histórico, denominação e imagem de elementos da geodiversidade, sentido do lugar, espiritual) é procedente da forte conexão entre o desenvolvimento social, cultural, religioso e o meio físico circundante.

- Valor Estético (paisagens locais, geoturismo, atividade de lazer, apreciação à distância, geoarquitetura) segundo Nascimento, Ruchkys e Mantesso-Neto (2008b), o valor estético atribuído a geodiversidade também é de difícil compreensão, pois também não é possível quantificá-lo. Percebe-se que a admiração da paisagem é praticada de forma pessoal, ou seja, muita gente acha a paisagem bonita, mas definir qual paisagem é mais bonita do que a outra é algo contestável.

-Valor Econômico (energia, minerais industriais, minerais metálicos, gemas, fósseis, minerais para a construção, solo) é mais fácil de identificar, pois já estamos acostumados a dar valor aos bens e serviços ambientais.

-Valor Funcional (plataformas, armazenamento e reciclagem, saúde, enterro, controle de poluição, química da água, funções do solo, funções do geossistema, funções do ecossistema) é visto sob dois aspectos: o valor da geodiversidade in situ, de maneira útil ao homem, como base para a realização de varias atividades humanas (construções de barragens, estradas, cidades e outros) ou no armazenamento de certas substâncias (águas subterrâneas, aterros etc); e o valor enquanto substrato para a sustentação dos sistemas físicos e ecológicos referindo-se as populações de animais e plantas em locais em que geodiversidade determinou as condições ideais para a formação e o desenvolvimento. 
- Valor Científico e Educativo (investigação científica, história da terra, pesquisa geológica, monitoramento ambiental, educação e formação de professores). Segundo Nascimento, Ruchkys e Mantesso-Neto (2008b) o valor científico tem como base o acesso e posterior estudo da geodiversidade, tanto em âmbito fundamental quanto aplicado, enquanto que o valor educativo está intimamente relacionado à educação em ciências da Terra, podendo ocorrer como atividades educativas formais (ensinos fundamental, médio e superior) ou informais (público não escolar).

\section{1. Área de Estudo}

O PEPB localiza-se ao norte do município de Araruna, na divisa dos Estados da Paraíba e Rio Grande do Norte, nas coordenadas $6^{\circ} 27^{\prime} 24,58^{\prime}$ S e 3540'32,99” W (Figura 01). É uma Unidade Conservação (UC) da categoria de proteção integral segundo o Sistema Nacional de Unidades de Conservação - SNUC (BRASIL, 2000). Foi criado pelo Governo do Estado da Paraíba partir do Decreto N. 20.889 de 07 de fevereiro de 2000 (PARAÍBA, 2000), e possui 157,27 hectares de extensão territorial.

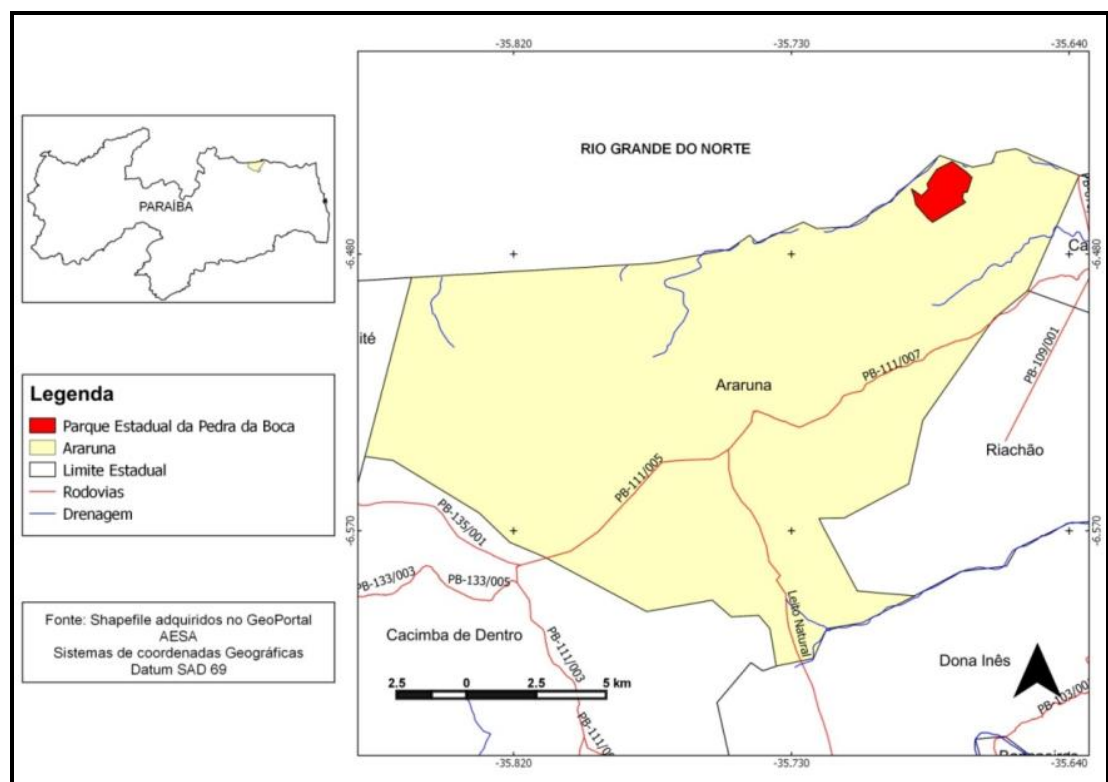

Figura 01: Mapa de Localização do Parque Estadual da Pedra da Boca (PEPB) Fonte: Barbosa (2016)

De acordo com o Decreto de criação, o objetivo do parque é preservar e aproveitar em atividades científicas, esportivas e turísticas as formações rochosas de características excepcionais, além das diversas grutas, algumas inscrições rupestres e a mata nativa do tipo caatinga (PARAÍBA, 2000).

O Parque é formado por um conjunto rochoso de beleza cênica singular (Figura 02) e significativo para a prática de diversos segmentos do turismo, com destaque para o ecoturismo, 
geoturismo e turismo de aventura, além de possibilitar o desenvolvimento de pesquisas científicas e atividades didáticas.

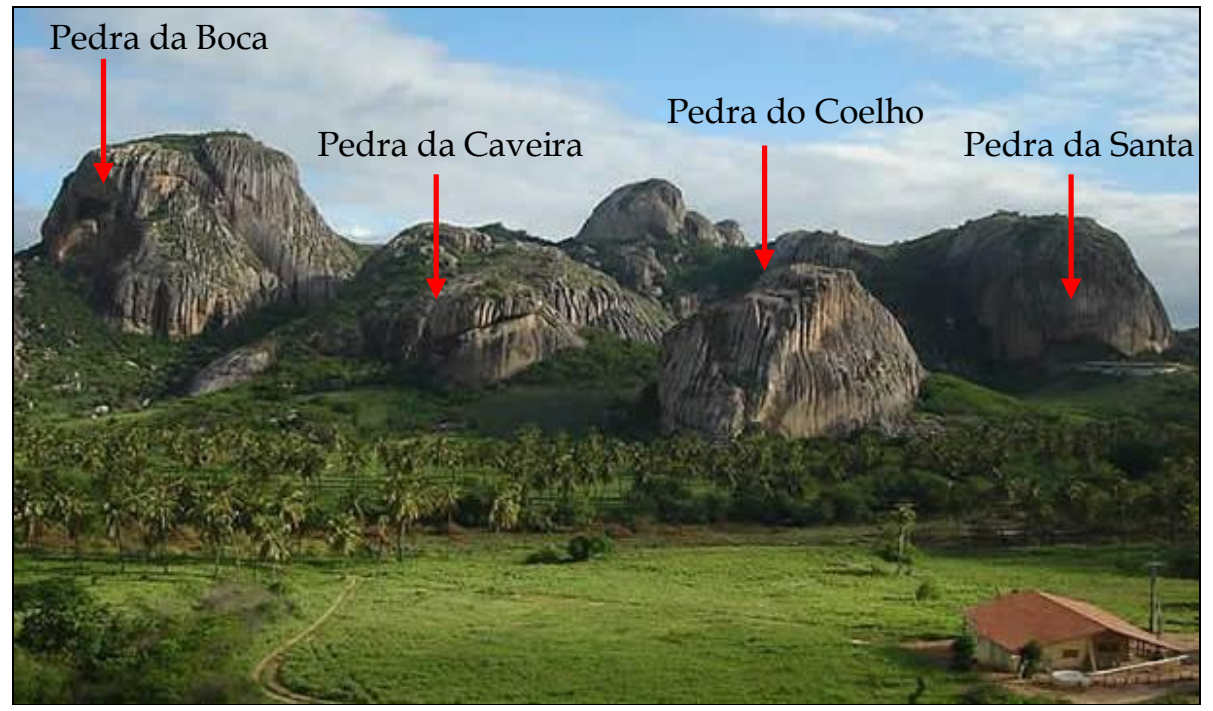

Figura 02: Vista panorâmica dos principais afloramentos rochosos do PEPB.

Fonte: Clebson Melo (2010).

\subsection{Características Ambientais do PEPB}

Com base em informações extraídas do mapa geológico da Paraíba (CPRM, 2002) a região onde se encontra o PEPB pertence ao ambiente geológico ígneo, inserindo-se na unidade geológica Suíte Intrusiva Shoshonitica-ultrapotássica Triunfo. O parque está inserido nos contrafortes da Serra da Confusão (CAVALCANTE, 2012), e faz parte do Plúton Monte das Gameleiras, um corpo ígneo que apresenta uma área aflorante de cerca de $340 \mathrm{~km}^{2}$, sendo composto, segundo Guimarães (2012), basicamente de rochas graníticas porfiríticas com textura grossa e fenocristais de feldspato apresentando enclaves dioríticos.

O nome do Parque advém de uma feição erosiva presente em um dos afloramentos rochosos, que apresenta semelhança com o formato de uma grande boca aberta, induzindo os turistas à uma curiosidade inicial que pode ser um critério importante para a escolha do local como destino turístico (BORBA, MENESES e CAVALCANTE, 2015). É comum a presença de extensas caneluras que podem se estender desde o cume até o nível de base dos afloramentos (Figura 03), geradas pela decomposição da rocha por conta do escoamento das águas superficiais e ao ataque do ácido húmico proveniente da decomposição da vegetação. 


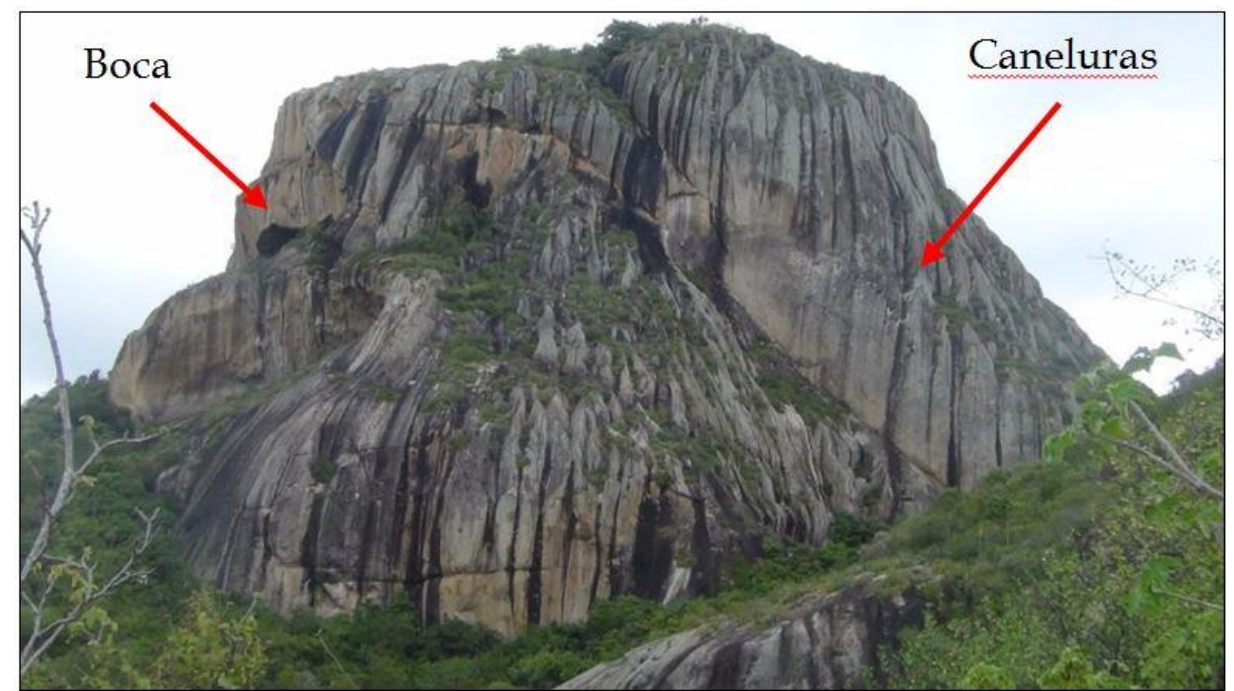

Figura 03: Afloramento onde se localiza a geoforma da Boca, com destaque para as caneluras verticais. Fonte: Acervo particular dos autores (2016)

A UC tem como um dos principais atrativos o geossítio Pedra da Boca que dá nome ao parque, composto de um grande afloramento rochoso com aproximadamente 336 metros de altura e que apresenta um abrigo formado por erosão diferencial entre os granitos e os dioritos, associada ainda com movimentos de massa do tipo queda de blocos. A cavidade (boca) tem cerca 87 metros de largura, 35 metros de profundidade e aproximadamente 50 metros de altura (GUIMARÃES, 2009). O mesmo processo de formação da "boca" pode ser observado também nas formações conhecidas como Pedra da Caveira e Pedra do Coelho (Figura 04), também situadas no interior do Parque.

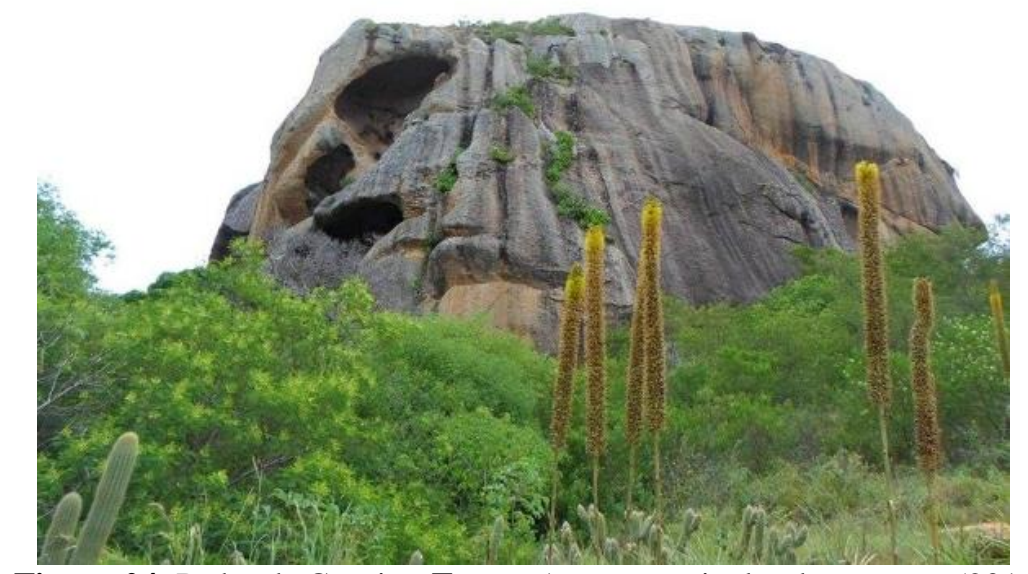

Figura 04: Pedra da Caveira. Fonte: Acervo particular dos autores (2016)

Além das caneluras, o bloco rochoso é caracterizado, ainda por apresentar cavidades "alveoladas", denominadas de "tafone" provenientes do intemperismo diferencial nos enclaves dioríticos presentes na massa granítica (GUIMARÃES, 2009), associadas, ainda, à erosão eólica. 


\section{RESULTADOS E DISCUSSÃO}

Como forma de apresentar os principais valores dos elementos da geodiversidade presentes no PEPB, elaborou-se um quadro indicativo (Quadro 01) onde foram listados os valores e subvalores observados na UC. Em seguida foram descritos e exemplificados cada um dos valores observados para a área do parque.

Ressalta-se nesse ponto que, a não identificação de algum dos valores ou subvalores não significa que os mesmo não existam, considerando que o desenvolvimento de pesquisas nos mais diversos campos das ciências e com métodos e técnicas diferenciadas podem fazer surgir elementos que ainda não tenham sido reconhecidos em sua totalidade da à restrições tecnológicas ou lacunas em certas áreas do conhecimento para a região onde se insere o parque.

Quadro 01: Valores da Geodiversidade PEPB.

\begin{tabular}{|l|c|c|}
\hline \multicolumn{1}{|c|}{ Tipos de Valor } & Subvalor & \\
\hline Valor Intrínseco & Valor intrínseco & $\mathrm{X}$ \\
\hline \multirow{3}{*}{ Valor Cultural } & Folclórico & $\mathrm{X}$ \\
\cline { 2 - 3 } & Arqueológico/ Histórico & $\mathrm{X}$ \\
\cline { 2 - 3 } & Espiritual & $\mathrm{X}$ \\
\cline { 2 - 3 } & Sentido/ Lugar & $\mathrm{X}$ \\
\hline \multirow{4}{*}{ Valor Estético } & Paisagens Locais & $\mathrm{X}$ \\
\cline { 2 - 3 } & Geoturismo & $\mathrm{X}$ \\
\cline { 2 - 3 } & Atividade de lazer & $\mathrm{X}$ \\
\cline { 2 - 3 } & Apreciação à distância & $\mathrm{X}$ \\
\cline { 2 - 3 } & Inspiração artística & $\mathrm{X}$ \\
\hline \multirow{3}{*}{ Valor Funcional } & Estocagem e reciclagem & $\mathrm{X}$ \\
\cline { 2 - 3 } & Funções geossistêmicas & $\mathrm{X}$ \\
\cline { 2 - 3 } & Funções do Ecossistema & $\mathrm{X}$ \\
\hline Valor Científico e Educativo & História da Terra & $\mathrm{X}$ \\
\cline { 2 - 3 } & Educação e treinamento & $\mathrm{X}$ \\
\hline
\end{tabular}

Dos sete valores sugeridos por Gray (2004), foram identificados no PEPB 06 deles e dos 32 subvalores possíveis foram observados 15 (quinze), o que já demonstra o grande potencial da geodiversidade da área para fins diversos.

Conforme apresentado no início do trabalho, o valor intrínseco é inerente a todo e qualquer elemento da geodiversidade, tenha ele ou não algum valor de uso para a humanidade, sendo assim não cabe discutir esse valor e, portanto, consideramos que o parque o possui.

$\mathrm{O}$ valor cultural apresenta-se em quatro subvalores. Do ponto de vista do folclore, existem lendas que são contadas por moradores da região sobre o parque, por exemplo, o poema de Elizabete Faustino "A princesa da Pedra da Boca", conta a lenda de um reino encantado. O subvalor arqueológico é traduzido na existência de pinturas rupestres (Figura 05) na Pedra da Santa, Pedra do 
Forno e Pedra do Babuíno. Estas pinturas correspondem a hieróglifos da Tradição Nordeste, possivelmente tendo sido produzidas pelos índios Tarairius e Paiacus que habitavam a região em tempos remotos (CAVALCANTE, 2007).

A presença do santuário, do oratório e a realização mensal das missas em honra a Nossa Senhora de Fátima na Pedra da Santa representam o subvalor espiritual, enquanto que a relação de pertencimento da população e a presença das formações rochosas em representações artísticas, em fachadas de edificações comerciais e na nomenclatura de empreendimentos comerciais nos municípios de Araruna (PB) e Passa e Fica (RN), constituem o sentido de lugar (Figura 05).
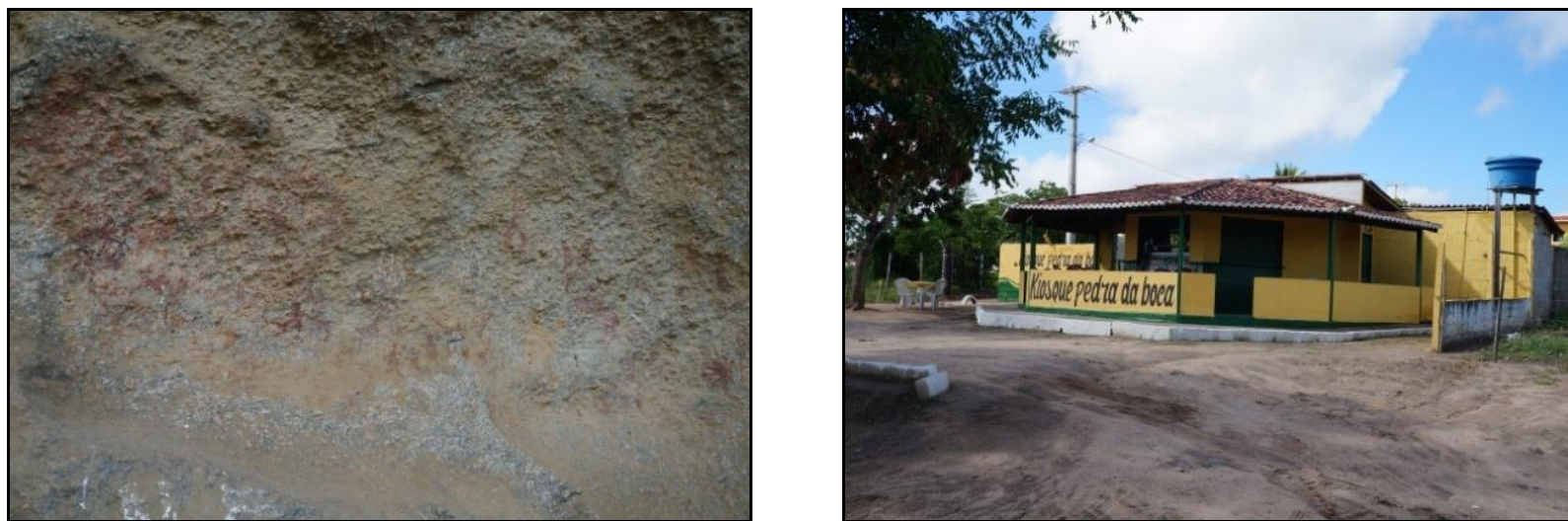

Figura 05: Pinturas Rupestres na Pedra da Santa (esquerda). Quiosque na estrada de acesso ao Parque (direita). Fonte: Elisabete Barbosa (2016).

O valor estético é visivelmente notado a partir das formações rochosas que compõem o geopatrimônio do Parque. Um traço marcante da paisagem do parque são as geoformas, definidas por Borba e Meneses (2013) como sendo afloramentos rochosos que apresentam semelhanças com imagens do cotidiano como rostos e formas de animais, fato que fez os autores atribuírem ao parque o título de "parque dos gigantes".

O complexo rochoso é um ícone da paisagem local podendo ser apreciado in loco ou ainda a partir de materiais de divulgação (folders, campanhas publicitárias) do governo do Estado, por exemplo. A prática de atividades de lazer, enquanto que o valor referente à inspiração artística pode ser verificado em produções para a televisão, como no caso do Programa Aventura Selvagem, da emissora SBT, no ano de 2013 com o apresentador Richard Rasmussen e outras mídias.

Para o valor funcional destaca-se que os inselbergs presentes no Parque possibilitam a formação de solos que doa sustentação à vegetação típica da região; a retenção de água nos depósitos de colúvio que se acumulam no sopé dos inselbergs e a manutenção de um microclima diferenciado das regiões do entorno.

O parque pode ser visto como um laboratório vivo, pois nele é possível o desenvolvimento de estudos sobre o meio abiótico, com as expressivas formações geomorfológicas e geológicas que 
compõem o batólito do Monte das Gameleiras, e sobre o meio biótico, assim sendo um ambiente propício para o desenvolvimento de diversas atividades escolares, pesquisa científica e de educação ambiental, contribuindo na formação de diversos profissionais, expressando-se, assim, o valor científico e educacional do parque.

\section{CONSIDERAÇÕES FINAIS}

A partir da identificação dos valores da geodiversidade fica evidente a importância geológica e geomorfológica do PEPB, que apresenta expressivos valores cultural, intrínseco, funcional e científico/educacional, que podem ser mais bem trabalhados para desenvolver novas vertentes do turismo que sejam mais adequadas às características ambientais daquela UC, a exemplo do geoturismo.

Não foi encontrado material cartográfico temático com detalhes de área do Parque durante a pesquisa de referências, o que dificulta a gestão territorial e o planejamento da UC. Como sugestão para trabalhos futuros indica-se a elaboração do mapeamento das trilhas, identificação de pontos de interesse geoturístico e inclusão da temática da geodiversidade e da geoconservação quando da elaboração do plano de manejo e do zoneamento ambiental por parte dos órgãos gestores, como forma a servir de suporte às ações de planejamento e gestão e possibilitar a efetiva implementação do parque enquanto instrumento de conservação e educação.

\section{REFERÊNCIAS}

BARBOSA, E.N. Parque Estadual da Pedra da Boca: um olhar sobre sua geodiversidade e situação atual. Trabalho de Conclusão de Curso (Graduação em Ecologia) - Universidade Federal da Paraíba. 2016. BORBA, C. S. ; MENESES, L.F. Geoformas: potencial do Cariri Paraibano. In: GeoBRheritage Simpósio Brasileiro de Patrimônio Geológico, 2013, Ouro Preto. GeoBRheritage - II Simpósio Brasileiro de Patrimônio Geológico, 2013.

BORBA, C. S. ; MENESES, L.F ; CAVALCANTE, M. B. Pedra da Boca: o parque dos gigantes. In: XVI Simpósio Brasileiro de Geografia Física Aplicada, 2015, Teresina. Territórios Brasileiros: dinâmicas, potencialidades e vulnerabilidades, 2015. p. 3671-3678.

BRASIL. Lei no 9.985, de 18 de julho de 2000. Institui o Sistema Nacional de Unidades de Conservação da Natureza e dá outras providências. Brasília, DF, 2000.

CAlvalcante, M. B. Parque Estadual da Pedra da Boca/PB: um olhar sobre o planejamento do ecoturismo em unidades de conservação na Paraíba. OKARA: Geografia em debate, João Pessoa, v.1, n. 2, p. 62-78, 2007. 
CAlvalcante, M. B. Parque Estadual Pedra da Boca (Araruna/PB): uma avaliação sobre as atividades turísticas e as ações de gestão territorial. Dissertação de Mestrado apresentada ao Programa de Pós-Graduação e Pesquisa em Geografia da Universidade Federal do Rio Grande do Norte. Natal, 2012, 146 p.

GRAY, M. Geodiversity: valuing and conserving abiotic nature. John Wiley and Sons, England. 434 p.

CPRM. Geologia e Recursos Minerais do Estado da Paraíba. Recife, 2002.

guimarães, T. O. Caracterização física da área do Parque Estadual da Pedra da Boca Araruna/PB. Monografia de Graduação, Departamento de Geografia/UFPB, 2009. 70 p.

GUIMARÃES, T. O.; MARIANO, G.; SEABRA, G. Estratégia de Geoconservação através da inventariação e quantificação de geossítios: Parque Estadual da Pedra da Boca - Plúton Monte das Gameleiras Araruna/PB. Estudos Geológicos (UFPE), v. 22, p. 77-92, 2012.

MANTESSO-NETO, V. Geodiversidade, geoconservação, geoturismo, patrimônio geológico, geoparque: novos conceitos nas geociências do século XXI. In: Anais... VI Congreso Uruguayo de Geologia, Uruguai, 2010.

NASCIMENTO, M. A.l., RUCHKYS. U. A., MANTENSSO-NETO. V. Geoturismo: um novo segmento do turismo no Brasil. Global Tourism. v. 3. n. 2. São Paulo, 2008a, p. 1-24.

NASCIMENTO, M.A.L. RUCHKYS, U.A., MANTESSO-NETO, V., Geodiversidade, Geoconsevação e Geoturismo: trinômio importante para a proteção patrimônio geológico. São Paulo: Sociedade Brasileira de Geologia, 2008-b. 86 p.

PARAIBA. Decreto n. ${ }^{\circ} 20.889$, de 07 de fevereiro de 2000. Cria o Parque Estadual da Pedra da Boca, e dá outras providências.

SEBRAE. Turismo no Brasil: Termo de Referência para a Atuação do Sistema SEBRAE. Brasília: SEBRAE, 2010.

Recebido em: 14/08/2016

Aceito para publicação em: 01/10/2016 